\title{
Influence of plate surface protuberance size and shape on the production of pellets by extrusion-spheronisation
}

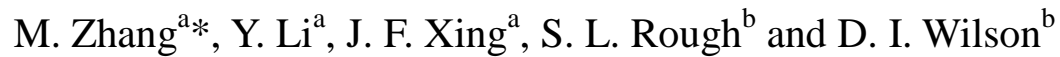 \\ ${ }^{a}$ School of Pharmacy, Xi'an Jiaotong University, No. 76, Yanta West Road, Xi'an \\ Shannxi, 710061, P. R. China \\ b Department of Chemical Engineering and Biotechnology, New Museums Site, \\ Pembroke Street, Cambridge, CB2 3RA, U.K.
}

Abstract

The influence of spheroniser plate surface protuberance geometry on pellets produced from spheronisation of paste extrudates was investigated using a model paste material (45 wt \% microcrystalline cellulose/water). Four cross-hatched pattern plates of different dimensions and/or shape of the surface protuberances were studied in terms of their effect on pellet water content, spheronisation yield, pellet size and shape distributions, and surface morphology. In addition, the effect of the relative size of extrudates to protuberances was investigated by comparing pellets generated from 1 and $2 \mathrm{~mm}$ diameter extrudates. In this study, all the plates have the same groove line arrangement but differ in surface protuberance dimensions and/or shape, and so the focus differs from that of Michie et al. (2012) who investigated plates of different groove line arrangement.

For all pellets the water content decreased with spheronisation time, more so for samples made from $2 \mathrm{~mm}$ extrudates. A systematic effect of protuberance geometry on the product yield (a measure of losses due to fines) was evident for both extrudate sizes, with yields decreasing in the order (large studs), (pyramidal), (saw-toothed), and (small studs). Analysis of two-dimensional images of dried pellets indicated that the $2 \mathrm{~mm}$ diameter extrudates generated pellets with narrower size distributions and better shape quality parameters (aspect ratio and circularity). This was confirmed via SEM images showing the surface morphology. The results indicate that the size of extrudates relative to the plate features is important and should be investigated further.

Keywords: Paste, Extrusion-spheronisation, Plate surface protuberances, Pellet properties

\footnotetext{
* Corresponding author. Tel.: +86 02982655139;

E-mail address: m.zhang904@ xjtu.edu.cn (M. Zhang).
} 


\section{Introduction}

Extrusion-spheronisation (E-S) is a multi-stage mechanical pelletisation process which produces granules of high sphericity. Particulate solids are firstly mixed with a liquid binder to create a dense suspension or paste, which is then extruded through dies or screens (effectively multi-holed dies with short die land length) to give cylindrical extrudates. The extrudates are then broken up and rounded on a rotating friction plate. E-S is widely used in the pharmaceutical, catalyst and food industries, since it is able to generate pellets with a relatively smooth surface and of uniform size (diameters usually $0.5-1.5 \mathrm{~mm}$ ), shape and density (Liew et al., 2007). The high sphericity and narrow size and shape distributions allow further processing steps, such as coating and compaction, to be carried out with ease as the pellets exhibit good flowability. Pharmaceutical pellets containing small amounts of active pharmaceutical ingredient (API) manufactured by E-S exhibit a slower release profile than those produced by processes such as direct compaction of the dry powder or wet mass (Wilson and Rough, 2007). Moreover, Di Pretoro et al. (2010) reported that pellets could be produced with a high API loading (up to $90 \mathrm{wt} \%$, which could not be achieved using other techniques) by systematic optimisation of the E-S paste formulation.

Optimisation of the E-S process requires a good understanding of how the properties of the paste (determined by its formulation and mixing history, see Kleinebudde et al., 1999 and Boutell et al., 2002; Wilson and Rough, 2007) relate to its behaviour during extrusion and the subsequent spheronisation step. There is a sizeable body of literature on the extrusion of soft-solid pastes through single and multi-holed die plates for ram extrusion (Fielden et al., 1992a \& b; Rough et al., 2000; Rahman et al., 2002 and Zhang et al., 2011) and auger (single screw) extrusion (Englander et al., 2000; Weert et al., 2001; Botten et al., 2003 and Mascia, 2008), but relatively little on twin screw (Koster et al., 2010) and screen extrusion (Zhang et al., 2013a). The microstructure of the paste and its extrudates are influenced by their shear history, in 
turn affecting their spheronisation performance. Bryan et al. (2015a) demonstrated that the shear strain rate (estimated maximum values ranging from 265 to $2220 \mathrm{~s}^{-1}$ ) experienced by the paste during the mixing stage can modify the extrusion behaviour of simple microcrystalline cellulose (MCC) pastes, while Zhang et al. (2011) showed that the E-S performance of MCC pastes differed between ram and screen extrusion, even when the paste had been prepared by the same route.

There is a similar need to improve the understanding of the influence of spheroniser geometry on spheronisation. During spheronisation, centrifugal forces cause the extrudates to migrate quickly towards the outer rim of the plate and travel in a toroid near the bowl wall. The extrudates collide with each other, with the friction plate and the walls, breaking the extrudates into rods of various length and promoting rounding into pellets (Michie et al., 2012; Lau et al., 2014; Sinka et al., 2015). Spheronisation of soft pharmaceutical paste extrudates usually takes $2-10$ min according to Gamlen (1985), although Michie et al. (2012) performed their spheronisation tests for $12 \mathrm{~min}$.

The influence of the friction plate geometry and groove pattern has received relatively little attention. The groove pattern, also known as the hatching pattern, refers to the regular arrangement of surface groove lines on a plate. Cross-hatched and radial patterns (see Figure 1) are commonly used to provide high friction (Vervaet et al., 1995).

Michie et al. (2012) investigated three plates of different hatching patterns, namely cross-hatched, radial and striated edge patterns (see Figure 1 in Michie et al., 2012). The influence of the groove line arrangements on pellet size distribution, product yield, shape, mechanical strength, porosity and drug dissolution was studied. They found that the line arrangements affected the spheronisation yield, median pellet size, pellet mechanical strength and porosity. The striated edge plate appeared superior in terms of spheronisation yield, although the pellets produced using this plate had lower 
mechanical strength due to their porosity being greater. Their experimental results indicated that the groove patterns played a role in determining the final pellet quality. They compared the properties of pellets obtained from plates with different hatching patterns but they neither investigated the influence of the dimensions and/or shapes of protuberances for a given hatching pattern, nor the relative dimensions of extrudate size to the protuberances. This is the aim of the current work.

Liew et al. (2007) compared spheronisation of 1:3 MCC:lactose monohydrate pastes using cross-hatched and teardrop-studded friction plates (see Figure 2 in Liew et al., 2007) and reported that the former gave larger and more spherical pellets at a rim speed of $10 \mathrm{~m} \mathrm{~s}^{-1}$. Spheronisation scale-up is usually performed using rim/peripheral speed (Newton et al., 1995). They attributed the observed differences in pellet size and shape to the amount of frictional force exerted by the plate on the extrudates. They asserted that at a given rim speed, the rounded-edge of the teardrop studs and the lower density of studs per unit area of the plate gave fewer and less strong frictional interactions than the cross-hatched plate. Agglomeration, densification and rounding of the extrudates/pellets therefore proceeded at a lower rate, giving smaller and less spherical pellets after a given time. They were able to generate pellets of similar size and shape distribution to the cross-hatched plate by using a higher rotation speed (and hence rim velocity). No quantitative relationship between frictional forces and plate rim speed was postulated.

Schmidt and Kleinebudde (1998) investigated two plates with pyramidal protuberances which differed in element size. They found that higher pyramids with smaller bases, giving a larger friction surface, were more effective in transferring mechanical energy into kinetic energy. The paste they investigated had a solid matrix of 70\% lactose-monohydrate and 30\% microcrystalline cellulose PH101. Extrudates with lower water content ( 40.1 and $44.5 \% \mathrm{w} / \mathrm{w}$ of water in the extrudates) and plasticity were better shaped on this high friction plate. Nevertheless, agglomeration 
was more likely to happen for the wetter extrudates $(59.9 \% \mathrm{w} / \mathrm{w}$ of water) when the high friction plate was used. Their work showed that the protuberance size had some effects on the pellet quality, which merited further investigation.

The protuberance size and spacing of radial and striated edge patterns vary with the diameter of the plate, which gives rise to uncertainty in scale-up. In contrast, the protuberance size and spacing of cross-hatched patterns are independent of the plate diameter (Michie et al., 2012), with advantages for scale-up.

Cross-hatched patterns are more commonly used in China and the aim of this investigation was to determine the influence of surface protuberances of cross-hatched pattern plates on spheronisation for four of these designs, shown in Figure 2, differing primarily in shape and dimensions of the protuberances. The findings have wider significance for the understanding of the spheronisation step in E-S and provide guidance for industry in the selection of spheronisation plates to produce pellets with certain desired properties.

Extrudates were generated using a commercial screen extruder and spheronised using the plates in Figure 2. Plate A resembles that used by Lau et al. (2014), but they generated their extrudates using a ram extruder fitted with a multi-holed die. The objectives of the study are to determine the following: $(i)$ whether cross-hatched plates with differently sized and/or shaped protuberances are all able to produce acceptable pellets for pharmaceutical applications; and (ii) the effect, if any, of extrudate diameter (versus plate surface protrusion dimension), plate surface protuberance shape and spheronisation duration on pellet water content, spheronisation yield, pellet size and shape distributions, and surface morphology.

A $45 \mathrm{wt} \% \mathrm{MCC} /$ water paste, similar to the material employed by Lau et al. (2014) and Bryan et al. (2015b), was employed as a model material for producing pellets. 
MCC is widely used in E-S formulations and is considered the 'gold standard' excipient (Fechner et al., 2003; Dukić et al., 2007; Kranz et al., 2009): other excipients, as reviewed by Dukić-Ott et al. (2009), show less flexibility in formulation and processing conditions.

\section{Materials and Methods}

\subsection{Material}

Microcrystalline cellulose (MCC, Avicel PH101) was obtained from FMC biopolymer $^{\mathrm{TM}}$ (FMC Corporation, Philadelphia, USA). MCC is a white powder, insoluble in water and most organic solvents. The moisture content of the as-received MCC powder was $~ 3 \mathrm{wt} \%$, and its loose bulk density was $290 \mathrm{~kg} \mathrm{~m}^{-3}$ (manufacturer's certificate of analysis data sheet). MCC particle sizing analysis was carried out using a Beckman Coulter ${ }^{\mathrm{TM}}$ LS13320 laser diffraction particle size analyser (Beckman Coulter, Inc., 250 South Kraemer Boulevard Brea, USA) and gave particle sizes ranging from $1.7-257 \mu \mathrm{m}$ with a Sauter mean diameter (i.e. $D[3,2]$ ) of $49.4 \mu \mathrm{m}$. Deionised water was used to prepare the pastes.

\subsection{Methods}

\section{Paste preparation and drying}

The MCC/water paste was prepared following a similar procedure to that reported by Zhang et al. (2011). Dry MCC powder and deionised water, in mass ratio 45:55, were weighed out separately using an electronic balance (PTF-A2000, Hua Zhi Scientific Instrument Co. Ltd Fu Zhou, China). The dry powder was loaded into the bowl of a planetary mixer fitted with a K-shaped beater (Chef Classic KM353, Kenwood Ltd, Shanghai, China) and the deionised water was slowly added by pouring over a period of one minute while the beater stirred at its minimum speed. The mixture was then stirred for periods of 2, 3, 3 and 2 minutes at dial setting speeds of 1,2, 3 and 4, respectively (following the protocol employed by Zhang et al., 2011): mixing was paused after each period and any paste build-up on the walls returned to the mass 
using a spatula. The paste was then transferred into a sealed plastic sample bag and held at room temperature for at least one hour before extrusion to allow the water to equilibrate through the paste. The paste batch was discarded after 7 hours.

The initial paste water content, $w$ (wet basis), was determined by weighing out about $30 \mathrm{~g}$ of paste and drying it in a vacuum oven at $60{ }^{\circ} \mathrm{C}$ and $\sim 0.1$ mbar vacuum, or in a hot air oven at $60{ }^{\circ} \mathrm{C}$, until a constant mass was obtained.

\section{Extrusion-spheronisation}

Extrusion was performed using a lab-scale basket extruder (ZLB-80, Cheng Hang Xin Rong Hua Manufacturer, Zhang Jia Gang, China) fitted with a cylindrical (84 mm i.d.) 304 stainless steel perforated screen. The dimensions of the screens used to produce the extrudates are given in Table 1. Extrusion was driven by a 304 stainless steel blade which rotated at $52 \mathrm{rpm}$ and pushed paste from the inner chamber through the screen. The gap between the blade edge and the screen, $g$, was $1 \mathrm{~mm}$, giving an estimated shear strain rate in the gap, $\dot{\gamma}$, of $226 \mathrm{~s}^{-1}$ estimated from

$$
\dot{\gamma}=\frac{\text { velocity }}{\text { gapsize }}=\frac{(2 \pi \omega / 60) R}{g}
$$

Eq. 1

where $\omega$ is the blade rotational speed and $R$ is the radius of the blade. This shear strain rate is comparable to that of the laboratory roller screen (LRS) extruder employed by (Zhang et al., 2013a).

The densities of notional (initial) paste and extrudates were measured following the methods reported by Zhang (2012) and Zhang et al. (2013a), respectively. In the former, about $10 \mathrm{~g}$ of paste was loaded into a volumetric cylinder without tamping and the volume and mass measured. The latter was calculated by weighing out about $0.5 \mathrm{~g}$ of fresh extrudates and estimating their total volume from their combined length and assuming their diameter to be that of the screen holes. Each measurement was repeated at least three times and the average is reported. 
About $30 \mathrm{~g}$ of fresh extrudates was loaded into the spheroniser chamber (R-120, Chong Qing Li Pu Pharmaceutical Equipment Manufacturer, Co. Ltd, Chong Qing, China). The spheroniser plates (A-D, Figure 2) were all manufactured from 304 stainless steel with a diameter of $120 \mathrm{~mm}$. Spheronisation was performed at a constant plate rotational speed, $\omega_{\mathrm{S}}$, of $1600 \mathrm{rpm}$ (corresponding to a rim speed, $V_{\text {rim }}$, of $10 \mathrm{~m} \mathrm{~s}^{-1}$ ) for 2, 4, 6, 8, 10 or $12 \mathrm{~min}$. This rim speed was also investigated by Lau et al. (2014), where a similar formulation was used for lab-scale experiments and pellets of acceptable size and shape were generated; here the speed is also the same as that used by Liew et al. (2007, $10 \mathrm{~m} \mathrm{~s}^{-1}$ ), where the experiments were performed using an industrial scale radial extruder on $1.38 \mathrm{~kg}$ of MCC/lactose/water paste (water content: $27.5 \mathrm{wt} \%)$.

Wall build-up, where pellets adhered to the wall of the spheroniser chamber, became noticeable after about 6 minutes of spheronisation at $1600 \mathrm{rpm}$. The amount adhering to the wall when processing $1 \mathrm{~mm}$ extrudates was small, but was noticeably larger for $2 \mathrm{~mm}$ extrudates. For the latter tests, spheronisation was stopped momentarily after $8 \mathrm{~min}$ and $10 \mathrm{~min}$ and material on the wall was returned to the bed before restarting rotation.

The mass of extrudates loaded into the spheroniser and the fresh pellets obtained after spheronisation were both weighed and their water content measured as described above. Each experiment was repeated at least three times. The yield of pellets on a dry basis, $Y$, was calculated from

$$
Y(\%)=\frac{m_{\mathrm{p}} \times\left(100-w_{\mathrm{p}}\right)}{m_{\mathrm{ex}} \times\left(100-w_{\mathrm{ex}}\right)}
$$
where $m_{\mathrm{p}}$ is the mass of the pellets, $w_{\mathrm{p}}$ is their water content, $m_{\mathrm{ex}}$ is the mass of the fresh extrudates and $w_{\mathrm{ex}}$ is their water content. The percentage lost, i.e. 100-Y, gives an indication of the total amount of material lost, which arises from fines escaping from the gap between the plate and the bowl, residual material stuck in grooves, and 
material adhered to the walls.

\section{Pellet Characterisation}

For pellet size and shape examination, dry pellets were initially sieved through a $2000 \mu \mathrm{m}$ mesh followed by a $355 \mu \mathrm{m}$ mesh in order to remove oversized pellets and fines, respectively. The amount of fines in the final product (on a dry basis) was small for both 1 and $2 \mathrm{~mm}$ extrudate cases. A riffler was used to select about one hundred and twenty pellets for further examination. Pellet size and shape analysis was performed using a BT-1600 image analysis system (Bettersize Instrument Ltd, Dandong, China), fitted with a $0.7 \times$ magnification lens. Pellet size was monitored comparable to these values. using the circle equivalent diameter, $d_{\mathrm{CE}}$, this being the diameter of a circle with an area equal to the projected area of the pellet, $A_{\mathrm{p}}$, i.e. $d_{\mathrm{CE}}=\left(4 A_{\mathrm{p}} / \pi\right)^{0.5}$. The pellet size was reported in a non-dimensional form by dividing $d_{\mathrm{CE}}$ by the diameter of the screen hole, $D$. Several parameters could be used to quantify pellet shape: this work employs (i) the aspect ratio, $A R$, defined as $a_{2} / a_{1}$, where $a_{1}$ and $a_{2}$ are the largest diameter on a 2-D projection of a pellet and the length normal to it, respectively; and (ii) the mean circularity, $C$, calculated from $4 \pi A_{\mathrm{p}} / P^{2}$, where $P$ is the perimeter of the pellet image.

Drying caused the pellets to shrink. The extent of shrinkage was determined by measuring $d_{\mathrm{CE}}$ of 8-10 pellets before and after drying using image analysis. The pellet samples were selected randomly from the products obtained from spheronisation of 1 and $2 \mathrm{~mm}$ extrudates at $1600 \mathrm{rpm}$ for $12 \mathrm{~min}$ using plate A. Both sets showed a linear shrinkage of $26 \%$, with $d_{\mathrm{CE}} / D$ decreasing from to $1.03 \pm 0.13$ (standard error, $n=8)$ to $0.76 \pm 0.10$ for the $1 \mathrm{~mm}$ extrudates, and $d_{\mathrm{CE}} / D$ decreasing from to $0.78 \pm 0.20(n=10)$ to $0.58 \pm 0.16$ for the $2 \mathrm{~mm}$ extrudates. Rough and Wilson (2005) reported pellet shrinkage for $45 \mathrm{wt} \% \mathrm{MCC} /$ water pellets to be about $22 \%$, which is 
The surface morphology of selected extrudates and dried pellets was investigated by scanning electron microscopy (SEM, TM-1000, Hitachi Ltd, Japan) operated at $15 \mathrm{kV}$ under vacuum at a magnification of $50 \times$. The samples were sputter coated with a thin layer of platinum before scanning.

\section{Results and Discussion}

\subsection{Screen extrusion and extrudate properties}

Extrusion of the $45 \mathrm{wt} \% \mathrm{MCC} /$ water paste gave relatively long extrudates, typically about a few centimetres in length. Surface fractures were observed on the side of extrudates generated when the extrusion blade passed the holes, as illustrated by Figure 3. These differed from the fracture patterns on extrudates obtained from ram and LRS extrusion, where the fractures appear circumferentially (Zhang et al., 2013a and Rough and Wilson, 2005). This is postulated to arise from uneven strain distribution as the paste passes through the screen holes and the screen flexes.

The extrudate densities are reported in Table 1. The extrudate densities for both screen hole diameters are larger than the bulk density of the initial paste $\left(474 \pm 13 \mathrm{~kg} \mathrm{~m}^{-3}\right)$, confirming that the paste is compacted as it undergoes shearing and extrusion. The extrudates obtained with the $D=1 \mathrm{~mm}$ screen holes have a higher density, which is expected as a larger extrusion pressure is required to force the material through a smaller area (Benbow and Bridgwater, 1993). Bryan et al. (2015a) reported that extrudate densities and extrusion pressures are strongly related to the strain history of the paste, in tests on similar materials to the paste used here. The densities in Table 1 are noticeably smaller than those reported for extrudates produced from similar $45 \mathrm{wt} \% \mathrm{MCC} /$ water pastes (measured initial bulk density $477 \pm 9 \mathrm{~kg} \mathrm{~m}^{-3}$ ) using ram and LRS extrusion, at $1150 \pm 20 \mathrm{~kg} \mathrm{~m}^{-3}$ (Zhang, 2008) and $980 \pm 10 \mathrm{~kg} \mathrm{~m}^{-3}$ (Zhang et al., 2013a), respectively. These differences in extrudate density mean that spheronisation dynamics will differ (see Bryan et al., 2015a) and care has to be taken in comparing results between these studies.

The difference in extrudate densities between screen hole diameters in Table 1 is 
relatively modest in comparison to the differences between the extrudate density and initial paste density (as mentioned above). The effect of extrudate diameter on spheronisation performance was tested for all four plates at a spheronisation speed of $1600 \mathrm{rpm}$. For plates A, B and C (as shown in Figure 2) the ratio of $1 \mathrm{~mm}$ extrudate diameter (taken as the screen hole diameter) to protuberance height, $D / H$, is approximately 1 , so that cylindrical extrudates and their fragments could readily lodge in the surface region. This is less likely for the $2 \mathrm{~mm}$ extrudates. Similar differences are expected to apply for the saw-toothed protuberances on plate D. A similar geometric argument can be applied to the spacing, i.e. $G / D$, where $G=S-W$, as a larger spacing makes it easier for extrudates or pellets to reside in this region.

The evolution of pellet water content, yield, size and shape distributions and surface morphology were all studied. Spheronisation tests were run for up to $12 \mathrm{~min}$, after Michie et al. (2012). Tests could be run for longer durations but there is a steady loss of water with time and this is likely to affect the rheology/deformation behaviour of the extrudates and their spheronisation performance.

\subsection{Water content and yield of spheronisation products}

Figure 4(a) shows that the water content for pellets generated from 1 and $2 \mathrm{~mm}$ extrudates both decreased with time. This is due to continuous centrifugation and evaporation from the pellet surfaces. The initial water content differs from the notional paste composition (55 wt\% water) owing to residual moisture in the MCC powder. The water contents for $D=1 \mathrm{~mm}$ pellets show significant scatter and decrease from about $55.7 \mathrm{wt} \%$ at $0 \mathrm{~min}$ (i.e. fresh extrudates) to $54.5 \mathrm{wt} \%$ (an average of the water content of the products from the four plates) after $12 \mathrm{~min}$. There is noticeably less scatter with the $D=2 \mathrm{~mm}$ pellets and the water content decreases to an average of $53.7 \mathrm{wt} \%$ after $12 \mathrm{~min}$. The difference between plate designs with $1 \mathrm{~mm}$ extrudates is not statistically significant. 
The difference in final pellet water contents between $D=1$ and $2 \mathrm{~mm}$ extrudates is about $1 \mathrm{wt} \%$. The water content of $D=1 \mathrm{~mm}$ pellets does not change much after $8 \mathrm{~min}$, but that of the $D=2 \mathrm{~mm}$ pellets continues to decrease. This is attributed to the size of the pellets, discussed in detail later (Figure 5): the $D=2 \mathrm{~mm}$ pellets are larger than the protuberances and tend to continue to move on the friction plate, enhancing convective mass transfer. The wall build-up referred to earlier is consistent with the pellets continuing to move and the surfaces becoming more cohesive owing to water being driven to the surface by continued collisions.

The corresponding yield data are presented in Figure 4(b). In general, the yield decreases with time. This is consistent with experimental observations that the material lost was mainly due to loss of fines through the gap between the plate and the bowl during spheronisation and more fines were evident in the space beneath the plate after longer spheronisation tests. A systematic effect of plate surface protuberances is evident for both extrudate sizes, with yields decreasing in the order C, A, D, B. The yields for A and D (the pyramidal and saw-toothed protuberances) with $D=2 \mathrm{~mm}$ extrudates are effectively identical. The difference for the $D=1 \mathrm{~mm}$ extrudates is not statistically significant: more tests would be needed to increase the level of confidence in this result. Whereas the yields for the $D=1 \mathrm{~mm}$ extrudates do not change over time, those for plates A, B and D with $D=2 \mathrm{~mm}$ decrease noticeably over the first 6 minutes. This is consistent with the earlier speculation that the $2 \mathrm{~mm}$ extrudate pellets are larger than the spacing between the protuberances; the pellets are not 'trapped' in the grooves, and hence move continuously, thus increasing the number of collisions on the friction plate during spheronisation, which in turn may generate more fines. The final yield values in Table 2 show that plate $\mathrm{C}$ gives similarly good performance for both extrudate sizes, indicating that this geometry is superior in terms of spheronisation yield, which is critical when the active pharmaceutical ingredient (API) is expensive. 


\subsection{Pellet size and shape distributions}

The pellets obtained after $12 \mathrm{~min}$ were dried and sieved using a pair of 2000 and $355 \mu \mathrm{m}$ meshes. About $99 \%$ (by mass) of the pellets were retained above the $355 \mu \mathrm{m}$ mesh. The results from the image analysis are presented in Figure 5: the mean size and shape factors are summarised in Table 3.

\section{Pellets from $D=1$ mm extrudates}

Figure 5(a,i) shows that all four plates gave multi-modal size distributions. Plate C gave a broader size distribution than those generated by plates $\mathrm{A}, \mathrm{B}$ and $\mathrm{D}$, with several modalities. This is reflected in a high standard deviation for $d_{\mathrm{CE}} / D$ in Table 3. Plates A and D gave bimodal distributions while that for B is almost unimodal with a shoulder and mode at $d_{\mathrm{CE}} / D \sim 0.53$ and 0.68 , respectively. The plate A distribution is reproduced in Figure 6 alongside fitted normal and log-normal distributions. Possible reasons for the variations in pellet size distributions for the different plates are: $(i)$ the size and spacing of the protuberances on plate $\mathrm{C}$ are both larger and the number of protuberances per unit area is fewer. As a result, the number of collisions between the extrudates and the friction plate are not sufficient to narrow the final pellet distribution; (ii) the size of the protuberances for plates A and B are similar, which yields the same mean $d_{\mathrm{CE}} / D$ and similar standard deviation values of their pellets (Table 3); (iii) the saw-toothed protuberances on plate D have sharp edges, at a $45^{\circ}$ angle, which could promote cutting and thereby generate smaller pellets as reflected by the smaller mode (of the size distribution curve in Figure $5(\mathrm{a}, i)$ ) and mean $d_{\mathrm{CE}} / D$ values (Table 3).

The pellets obtained with plates A and B were all of acceptable shape, with aspect ratios both greater than the threshold of 0.80 with a mean value of 0.94 and 0.95 (see Table 3), respectively, and small standard deviations $(\leq 0.05)$. The plot of aspect ratio with pellet size in Figure 5(b,i) shows noticeable variation for both plates $\mathrm{C}$ and $\mathrm{D}$ : neither satisfy the above quality threshold. These differences in shape are also 
reflected in the circularities reported in Table 3: plates A and B gave similarly good values whereas those of $\mathrm{C}$ and $\mathrm{D}$ are less satisfactory. Due to the unsatisfactory size distribution and/or low mean aspect ratio of the pellets, plates $\mathrm{C}$ and $\mathrm{D}$ are deemed to give unacceptable spheronisation products from $D=1 \mathrm{~mm}$ extrudates.

\section{Pellets from $D=2$ mm extrudates}

The pellet size distributions in Figure 5(a,ii) show some differences to the results obtained with $1 \mathrm{~mm}$ extrudates. In general, the size distributions of pellets from $2 \mathrm{~mm}$ extrudates were narrower, reflected in the smaller standard deviations in $d_{\mathrm{CE}} / D$ in Table 3. The differences suggest that not only the size and shape of the protuberances but also the ratio to extrudate diameter affect pelletisation.

The distribution for plate $\mathrm{A}$ is bimodal with a shoulder and two peaks at $d_{\mathrm{CE}} / D=0.61$, 0.69 and 0.74 , respectively. Plate $\mathrm{A}$ has a tail at higher $d_{\mathrm{CE}} / D$ values, giving it a wider distribution than the other three plates. This distribution is plotted alongside fitted normal and log-normal distributions in Figure 6(b): the tail is evident and there are noticeable shoulders on the modal peak, but this could be a result of the finite number (about 120) of pellets measured.

The size distribution curve of pellets obtained using plate B shows multiple peaks over a relatively broad distribution range, which is reflected by a higher standard deviation in Table 3. Plate $\mathrm{C}$ gives a tri-modal distribution, with peaks at $d_{\mathrm{CE}} / D=0.66$, 0.74 and 0.79 ; plate $\mathrm{D}$ gives a shoulder and single mode at $d_{\mathrm{CE}} / D=0.59$ and 0.69 , respectively. In terms of shape, Figure 5(b,ii) indicates that the larger pellets obtained with each plate do not satisfy the shape criteria, but these are relatively few in number: they represent approximately about $3 \%, 4 \%, 1 \%$ and $2 \%$ of the total number of pellets obtained from plates $\mathrm{A}, \mathrm{B}, \mathrm{C}$ and $\mathrm{D}$, respectively. The pellet shape quality is also reflected in the circularity data in Table 3. 


\section{Comparisons}

Table 3 shows that the pellets obtained from 1 and $2 \mathrm{~mm}$ extrudates have similar mean $d_{\mathrm{CE}} / D$ values when the same plate was used, except for plate $\mathrm{D}$ which produced unacceptable pellets for $D=1 \mathrm{~mm}$ extrudates. The standard deviation in $d_{\mathrm{CE}} / D$ is consistently smaller for $2 \mathrm{~mm}$ extrudates for plates A, C and D. The mean aspect ratios of the pellets from plates A and B appear to be independent of the screen hole diameter: the larger standard deviations for $D=2 \mathrm{~mm}$ extrudates are skewed by the presence of the poorer quality large pellets mentioned above. The circularity values exhibit the same trend as seen with aspect ratio. For plates $C$ and D, pellets generated from $D=2 \mathrm{~mm}$ extrudates exhibit higher mean aspect ratios and smaller corresponding standard deviations than those from the $1 \mathrm{~mm}$ extrudates, and there is no significant difference in the mean circularity between the pellet samples.

In general, the $2 \mathrm{~mm}$ diameter extrudates generated pellets with narrower size and superior shape distributions than those from the $1 \mathrm{~mm}$ extrudates. This result suggests that the ratio of extrudate diameter to protuberance height, $D / H$ (and spacing, $D / G$ ) is important and should be investigated further. Further investigation requires a systematic design of dimensions of both the extrudates and plate surface protuberances, supported by high speed camera analysis of pellet motion.

The mean $d_{\mathrm{CE}} / D$ values for all the acceptable pellets lie around 0.7 . This can be compared with the expected result for cylindrical extrudates breaking up into sections of length $D$, as reported by Harrison et al. (1985). Assuming conservation of volume, an extrudate of length $D$ will give a sphere of diameter $1.14 D$. Shrinkage of $26 \%$ during drying would give $d_{\mathrm{CE}} / D \sim 0.85$, which is larger than the observed value. The difference is attributed to compaction of the paste matrix during collisions as the density measurements indicate that the extrudate is not as dense as material prepared via other routes, so can be compacted further. 
Each pellet size data set was fitted to unimodal normal and log-normal distribution models. Examples of the fitting results are plotted alongside the raw data for plate A in Figure 6 and parameters are summarized in Table 4. The $D=1 \mathrm{~mm}$ data are better described by a normal distribution, whereas a log-normal distribution is preferable for the data sets with a tail (plate $\mathrm{D}$ and the $D=2 \mathrm{~mm}$ extrudates). The reason for the presence of more large (and less rounded) pellets with the $2 \mathrm{~mm}$ extrudates is likely to be related to the development of cohesive surfaces, promoting wall build-up and reducing the amount of collisions experienced by large pellets.

\subsection{Pellet surface morphology}

The SEM images in Figure 7 show differences in pellet surface structure as well as shape. The pellets generated from $D=2 \mathrm{~mm}$ extrudates are all rounded, reflecting the similarity in aspect ratios and circularity in Table 3 . The pellets from $D=1 \mathrm{~mm}$ extrudates produced using plates A and B are also rounded, whereas those produced with plates $\mathrm{C}$ and $\mathrm{D}$ are less regular, which is again consistent with the results in Table 3. The micrographs of extrudate surfaces for different diameters in Figure 7(e) show similar surface fractures (as mentioned in section 3.1), indicating that the differences in spheronisation performance is related to the collisions experienced on the plate.

With the exception of the pellets generated from $D=2 \mathrm{~mm}$ extrudates using plates A and $\mathrm{B}$, the images all show noticeable holes and dimples. These are particularly evident with pellets produced using plate $\mathrm{D}$, and relatively few for $D=1 \mathrm{~mm}$ with plate B. These features are unlikely to arise from drying as the same protocol (i.e. $60{ }^{\circ} \mathrm{C}$ and $\sim 0.1$ mbar vacuum) was employed for all pellets. Rather, they suggest that the number of collisions and deformation resulting from those collisions varies between the plates. Kinetic energy is transferred to the pellets by the plate rotation and this is dissipated as plastic work of deformation in collisions between pairs of pellets or between a pellet and the plate or wall. The images suggest that this process is more efficient for plates $\mathrm{A}$ and $\mathrm{B}$, and significantly less efficient for plate D. 
Moreover, the variation may result in different pellet spheronisation routes: the pellets from $1 \mathrm{~mm}$ extrudates were generated by folding of dumb-bells, which are more likely to cause holes and dimples as Rough and Wilson (2005) reported; and those from $2 \mathrm{~mm}$ extrudates were shaped and smoothed mainly via agglomeration that could generate smoother surfaces. High speed video analysis, similar to that employed by Koester and Thommes (2013), would be required to elucidate whether this is a result of smaller accelerations or fewer collisions for a given plate. The difference in rounding between 1 and $2 \mathrm{~mm}$ extrudates supports the earlier hypothesis that pellets with $D / H>1$ and $D / G>1$ are likely to continue in motion on the friction plate rather than become trapped between the protuberances.

The presence of large voids in the pellets is undesirable as uniformity in microstructure is compromised. Such voids will result in anisotropic strength, promote breakage and give non-uniform solute release. In this respect, the plate D pellets would be unlikely to be suitable for controlled release products or catalysts.

\subsection{Discussion}

The above results demonstrate measurable influences of friction plate geometry on spheronisation performance. Smaller protuberances, i.e. $D / H>1$ and $D / G>1$, favour rounding via more efficient collisions and the avoidance of pellets residing on the rotating plate. Industrial screens usually have $D=1$ or $1.5 \mathrm{~mm}$ and friction plate heights are typically $1 \mathrm{~mm}$, so this suggests that shorter protuberances should be used. This is broadly consistent with the difference in performance of plates B and C, although the spacing in these is also different: there is more space for a pellet to reside on the plate with $\mathrm{C}$.

Table 5 ranks the performance of each plate for the different extrudate diameters. The assessment is qualitative and one criterion may be more important to the end user than another. Weighting each parameter equally indicates that Plate A gives the best 
performance for both extrudate diameters, whereas the ranking for plates B-D change with $D$. This result confirms the need to consider the protuberance size and shape of the spheronisation friction plate when optimising the process performance.

This work has investigated the effect of plate geometry on spheronisation for a single paste formulation. The tendency of extrudates to lose water by evaporation, to fracture, to generate fines by attrition and to stick to the spheroniser wall are all influenced by paste formulation (particularly excipient nature and liquid binder content). The MCC-water paste employed here is a model paste in that it is relatively robust towards the aforementioned effects. There is often a period of development work required to optimise the spheronisation of a commercial formulation, as it is difficult to map formulation aspects directly to spheronisation performance: this work shows that friction plate geometry should be considered as part of this process.

\section{Conclusions}

The effect of plate surface protuberances on the pellet water content, yield, pellet size and shape, as well as the pellet surface morphology, was investigated for model MCC/water paste extrudates. The extrudates, generated using a commercial screen extruder, had surface fractures on one side, which was different from that of the extrudates generated by ram and LRS extrusion where the fractures are usually present circumferentially.

For each test, the pellet water content decreased with spheronisation time; however, no systematic difference between the four investigated plates was observed. The surface protuberance size and shape showed effects on both the yield of pellets and pellet size and shape distributions. It was found that plate $\mathrm{C}$, with large studs, was superior in terms of spheronisation yield for both the 1 and $2 \mathrm{~mm}$ extrudates, whereas the yields for plate B with small studs were the lowest. Plates A (pyramidal) and D (saw-toothed) showed a similar performance for both extrudates sizes. The pellets 
obtained from $2 \mathrm{~mm}$ diameter extrudates had generally narrower size distributions and better shape qualities than those obtained from $1 \mathrm{~mm}$ extrudates. Additionally, for a given spheronisation plate, different trends in pellet size and shape quality were observed for 1 and $2 \mathrm{~mm}$ extrudates, indicating that the ratio of plate protuberance dimensions to extrudate size had an important role in promoting extrudate/segment deformation during spheronisation. Further investigation would involve a systematic design of dimensions of the extrudate and plate surface protuberances and this is the subject of on-going work.

SEM analysis of the pellets obtained from $1 \mathrm{~mm}$ extrudates and several $2 \mathrm{~mm}$ extrudates showed large voids, which were particularly evident with the pellets generated using plate D. In comparison, pellets generated from $2 \mathrm{~mm}$ extrudates using plates A and B have relatively smooth surfaces, i.e. no surface holes or dimples, suggesting that the rotation of the two plates led to more efficient collisions and deformations. Pellets with large voids are not desired in some cases as they would be unsuitable for drug controlled release applications and stable catalysis performance. Although the experimental results showed that the pyramidal design (Plate A) gave a satisfactory performance under all four criteria, the results also suggested that there was a need for industry to optimise the plate surface protuberance size and shape in order to produce pellets with certain desired properties, and hence this study could provide some qualitative information for the selection of an appropriate friction plate. The relative dimensions of extrudate size and plate surface protuberance would need to be optimised further if it were intended for industrial manufacture.

\section{Acknowledgement}

This work was finically supported by the China Postdoctoral Science Foundation (Grant No.: 2014M550497). The authors thank Dr Edward Ishiyama for his assistance with the particle size distribution analysis. 


\section{Roman}

$a_{1} \quad$ Largest diameter on 2-D projection of pellet $\quad \mathrm{m}$

$a_{2} \quad$ Length normal to $a_{1} \quad \mathrm{~m}$

$A_{\mathrm{p}} \quad$ Projected area of pellet $\quad \mathrm{m}^{2}$

$A R \quad$ Aspect ratio

C Circularity

$d_{\mathrm{CE}} \quad$ Circle equivalent diameter of pellet $\quad \mathrm{m}$

D Diameter of screen holes $\quad$ m

$D[3,2] \quad$ Sauter mean diameter $\quad \mathrm{m}$

$g \quad$ Gap between blade edge and screen $\quad \mathrm{m}$

$G \quad$ Spacing between protuberances, $G=S-W \quad \mathrm{~m}$

$H \quad$ Height of protuberances on plate surface $\quad \mathrm{m}$

$m_{\mathrm{ex}} \quad$ Mass of extrudates $\quad \mathrm{kg}$

$m_{\mathrm{p}} \quad$ Mass of spheronisation product $\quad \mathrm{kg}$

$n \quad$ Number of pellets

$P \quad$ Perimeter of projected image of pellet m

$R \quad$ Radius of extrusion blade m

$R_{\mathrm{S}} \quad$ Radius of spheronisation plate m

$S \quad$ Spacing of protuberances on plate surface $\quad \mathrm{m}$

$V_{\text {rim }} \quad$ Spheronisation plate rim speed $\quad \mathrm{m} \mathrm{s}^{-1}$

w Initial paste water content $\%$

$w_{\mathrm{ex}} \quad$ Water content of extrudates $\%$

$w_{\mathrm{p}} \quad$ Water content of spheronisation product $\%$

W Width of top of protuberances on plate surface m

$Y \quad$ Yield of pellets on a dry basis $\quad \%$

566 Greek

$\dot{\gamma} \quad$ Shear strain rate $\mathrm{s}^{-1}$

Mean of $d_{\mathrm{CE}} / D$ for normal distribution; mean of $\ln \left(d_{\mathrm{CE}} / D\right)$ for $\log$-normal distribution

Standard deviation of $d_{\mathrm{CE}} / D$ for normal distribution; standard deviation of $\ln \left(d_{\mathrm{CE}} / D\right)$ for $\log$-normal distribution

$\omega \quad$ Extrusion blade rotational speed 


\section{References}

Benbow, J. J. and Bridgwater, J., 1993. Paste Flow and Extrusion. Clarendon Press, Oxford.

Botten, A. J., Burbidge, A. S. and Blackburn, S., 2003. A model to predict the pressure development in single screw extrusion, J. Mater. Process Tech., 135(2-3), 284-290.

Boutell, S., Newton, J. M., Bloor, J. R. and Hayes, G., 2002. The influence of liquid binder on the liquid mobility and preparation of spherical granules by the process of extrusion/spheronization, Int. J. Pharm., 238(1-2), 61-76.

Bryan, M. P., Kent, M. D., Rickenbach, J., Rimmer, G., Wilson D. I. and Rough, S. L., 2015a. The effect of mixing on the extrusion-spheronisation of a micro-crystalline cellulose paste, Int. J. Pharm., 479(1), 1-10.

Bryan, M. P., Atherton, L. N., Duffield, S., Rough, S. L. and Wilson, D. I., 2015b. Stages in spheronisation: Evolution of pellet size and shape during spheronisation of microcrystalline cellulose-based paste extrudates, Powder Technol., 270, 163-175.

Di Pretoro, G., Zema, L., Gazzaniga, A., Rough, S. L. and Wilson, D. I., 2010. Extrusion-spheronisation of highly loaded 5-ASA multiparticulate dosage forms. Int. J. Pharm., 402(1-2), 153-164.

Dukić-Ott, A., Thommes, M., Remon, J. P., Kleinebudde, P. and Vervaet, C., 2009. Production of pellets via extrusion-spheronisation without the incorporation of microcrystalline cellulose: A critical review. Euro. J. Pharm. and Biopharm. 71(1), 38-46.

Dukić, A., Mens, R., Adriaensens, P., Foreman, P., Gelan, J., Remon, J. P. and Vervaet, C., 2007. Development of starch-based pellets via extrusion/spheronisation. Euro. J. Pharm. and Biopharm. 66(1), 83-94.

Edwards, A. W. F., 1972. Likelihood (Expanded Edition). The Johns Hopkins University Press, Baltimore and London.

Engländer, A., Burbidge, A. and Blackburn, S., 2000. A preliminary evaluation of single screw paste extrusion, Chem. Eng. Res. Des., 78(A5), 790-794.

Fechner, P. M., Wartewig, S., Futing, M., Heilmann, A., Neubert, R. H. H. and Kleinebudde, P., 2003. Properties of microcrystalline cellulose and powder cellulose after extrusion/spheronization as studied by Fourier transform Raman spectroscopy and environmental scanning electron microscopy. Aaps Pharmsci. $5(4)$.

Fielden, K. E., Newton, J. M. and Rowe, R. C., 1992a. The influence of lactose particle-size on spheronization of extrudate processed by a ram extruder, Int. J. Pharm., 81(2-3), 205-224. 
Fielden, K.E., Newton, J. M. and Rowe, R.C., 1992b. A comparison of the extrusion and spheronization behavior of wet powder masses processed by a ram extruder and a cylinder extruder, Int. J. Pharm., 81(2-3), 225-233.

Gamlen, M. J., 1985. Pellet manufacture for controlled release, Manuf. Chem., 56(6), 55-59.

Harrison, P. J., Newton, J. M. and Rowe, R. C., 1985. The characterization of wet powder masses suitable for extrusion/spheronization, J. Pharm. Pharmacol., 37(10), 686-691.

Kranz, H., Jurgens, K., Pinier, M. and Siepmann, J.,(2009). Drug release from MCC- and carrageenan-based pellets: Experiment and theory. Euro. J. Pharm. and Biopharm., 73(2), 302-309.

Kleinebudde, P., Schroder, M., Schultz, P., Muller, B. W., Waaler, T. and Nymo, L., 1999. Importance of the fraction of microcrystalline cellulose and spheronization speed on the properties of extruded pellets made from binary mixtures, Pharm. Dev. Technol., 4(3), 397-404.

Koster, M. and Thommes, M., 2010. In-line dynamic torque measurement in twin-screw extrusion process, Chem. Eng. J., 164(2-3). 371-375.

Koester, M. and Thommes, M., 2013. Analysis of particle kinematics in spheronization via particle image velocimetry. Euro. J. Pharm. and Biopharm., 83(2), 307-314.

Lau, C.L.S., Yu, Q., Lister, V. Y., Rough, R. L., Wilson, D. I. and Zhang, M., 2014. The evolution of pellet size and shape during spheronisation of an extruded microcrystalline cellulose paste, Chem. Eng. Res. and Des., 92, 2413-2424.

Liew, C.V., Chua, S. M. and Heng, P. W. S., 2007. Elucidation of spheroid formation with and without the extrusion step, AAPS PharmSciTech., 8 (2007) $1-10$.

Mascia, S., 2008. Rheology and Processing of Pharmaceutical Pastes. PhD dissertation, Chemical Engineering. Cambridge, UK: University of Cambridge.

Michie, H., Podczeck, F. and Newton, J. M., 2012. The influence of plate design on the properties of pellets produced by extrusion and spheronization, Int. J. Pharm., 434(1-2), 175-182.

Newton, J. M., Chapman, S. R. and Rowe, R. C., 1995. The Influence of process variables on the preparation and properties of spherical granules by the process of extrusion and spheronisation, Int. J. Pharm., 120(1), 101-109.

Pretoro, G. Di., Zema, L., Gazzaniga, A., Rough, S. L. and Wilson, D. I., 2011. Extrusion-spheronisation of highly loaded 5-ASA multiparticulate dosage forms, Int. J. Pharm., 402(1-2), 153-164. 
Rahman, L., Rowe, P., Cheyne, A. and Wilson, D. I., 2002. Ram extrusion of potato starch dough through multi-holed dies, Food Bioprod. Process., 80(C1), 12-19.

Rough, S. L., Bridgwater, J. and Wilson, D. I., 2000. Effects of liquid phase migration on extrusion of microcrystalline cellulose pastes, Int. J. Pharm., 204(1-2), 117-126.

Rough, S. L. and Wilson, D. I., 2005. Extrudate fracture and spheronisation of microcrystalline cellulose pastes, J. Mat. Sci., 40, 4199-4219.

Schmidt, C. and Kleinebudde, P., 1998. Comparison between a twin-screw extruder and a rotary ring die press. Part II: influence of process variables. Euro. J. Pharm. and Biopharm., 45(2), 173-179.

Sinka, I. C., 2015. A model for the deformation of an ellipsoid subject to a large number of successive impacts with special reference to spheronisation, Powder Technol., 270, 592-598.

Vervaet, C., Baert, L. and Remon, J. P., 1995. Extrusion-Spheronisation - a Literature-Review, Int. J. Pharm., 116(2), 131-146.

Weert, X., Lawrence, C. J., Adams, M. J. and Briscoe, B. J., 2001. Screw extrusion of food powders: prediction and performance, Chem. Eng. Sci., 56(5), 1933-1949.

Wilson, D. I. and Rough, S. L., 2007. Extrusion-spheronisation. In: Salman, A.D., Hounslow, M.J. (Eds.), Granulation. Elsevier, Amsterdam, 2009, pp. 189-210.

Zhang, M., Rough, S. L., Ward, R., Seiler, C. and Wilson, D. I., 2011. A comparison of ram extrusion by single-holed and multi-holed dies for extrusion-spheronisation of microcrystalline-based pastes. Int. J. Pharm., 416(1), 210-222.

Zhang, M., 2012. Extrusion-Spheronisation of Cellulose-based Pharmaceutical Pastes. PhD dissertation. University of Cambridge.

Zhang, M., Mascia, S., Rough, S. L., Ward, R., Seiler, C. and Wilson, D. I., 2013a. A novel lab-scale screen extruder for studying extrusion-spheronisation, Int. J. Pharm., 455(1-2), 285-297.

Zhang, M., Wilson, D. I., Ward, R., Seiler, C. and Rough, S. L., 2013b. A comparison of screen and ram extrusion-spheronisation of simple pharmaceutical pastes based on microcrystalline cellulose, Int. J. Pharm., 456(2), 489-498. 

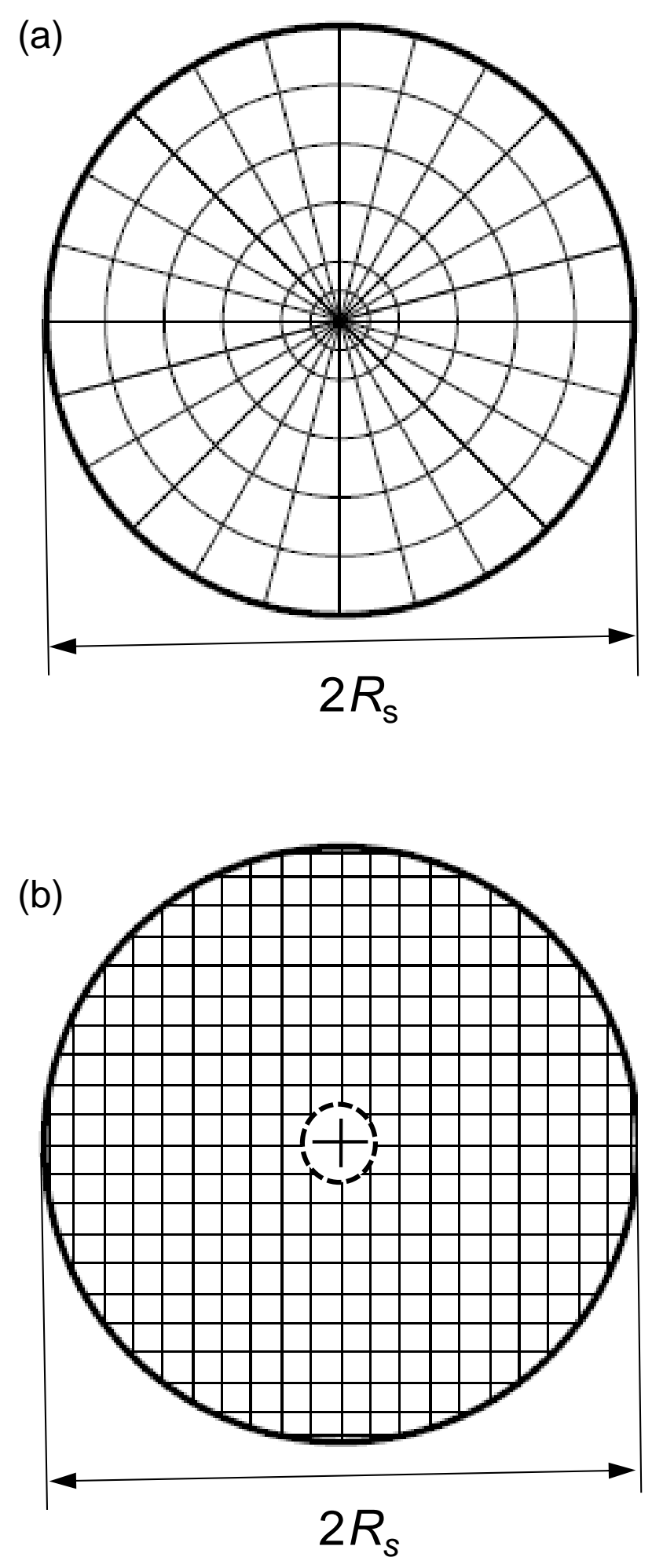

Figure 1 Geometry of spheronisation plates $(a)$ radial, $(b)$ cross-hatched (after Vervaet et al., 1995). The diameter of the plate is $2 R_{\mathrm{s}}$. 
A

(i)

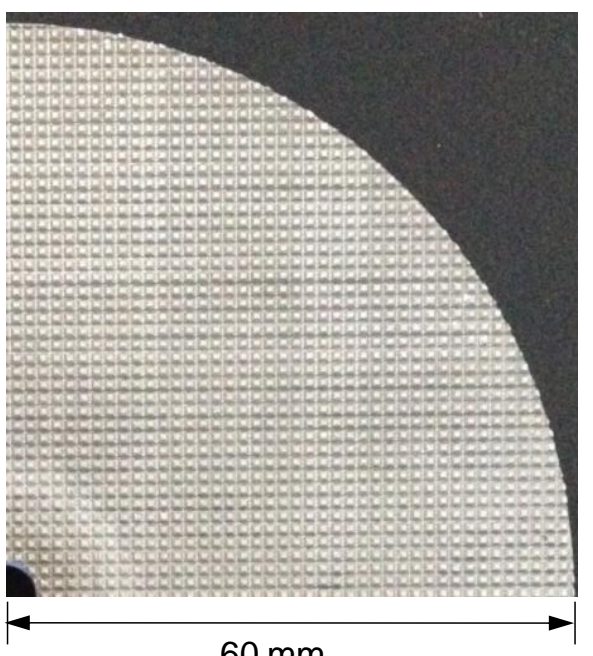

$60 \mathrm{~mm}$

Side view

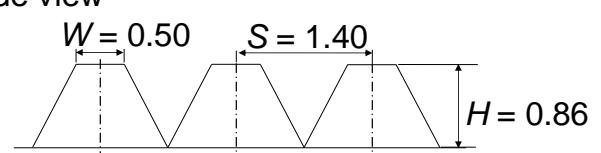

(ii)

Overview

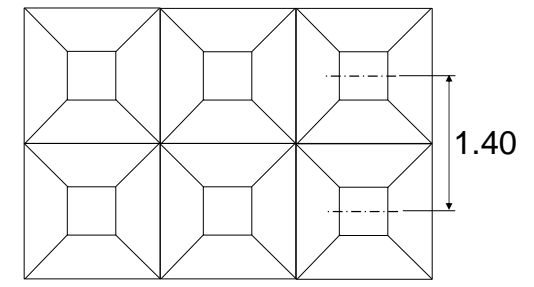

$S / H=1.6 \quad W / H=0.6$
B
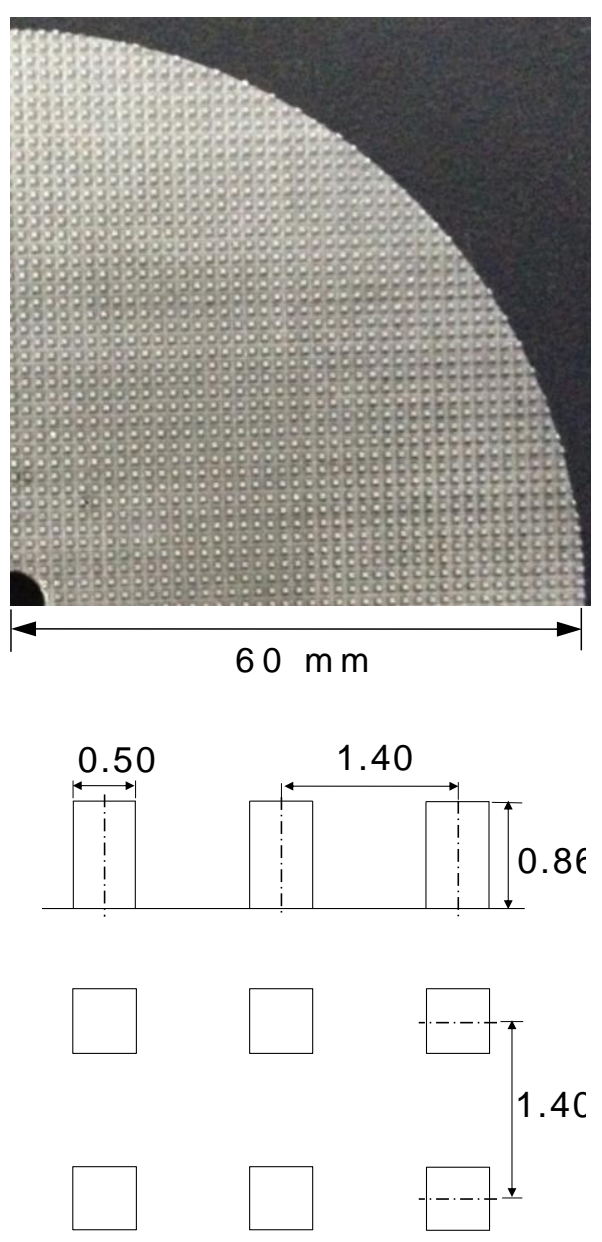

$S / H=1.6$

$W / H=0.6$

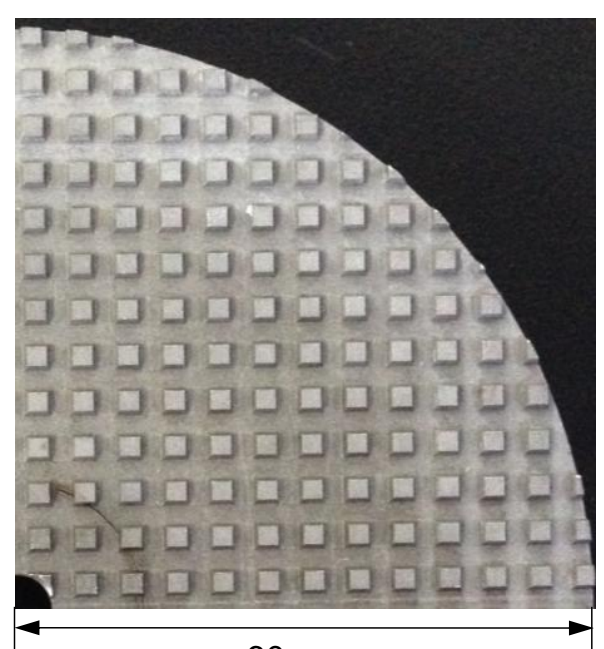

$60 \mathrm{~mm}$
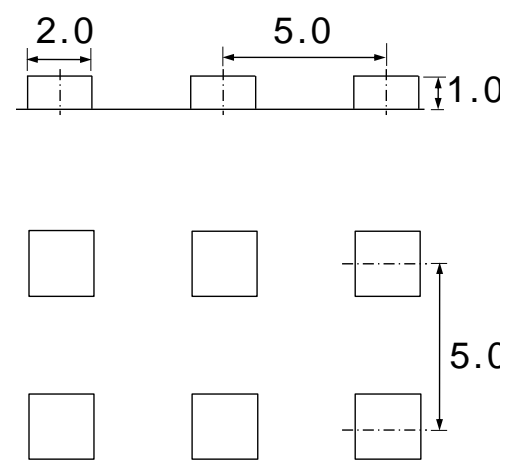

$S / H=5.0$

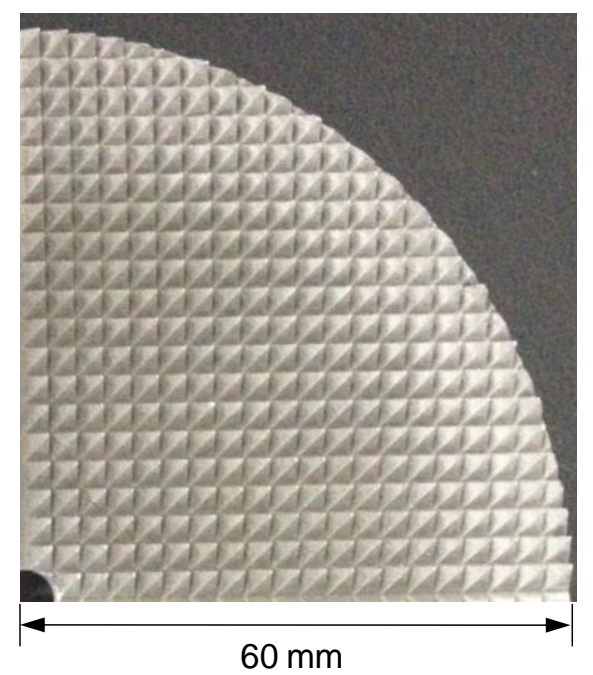

$60 \mathrm{~mm}$
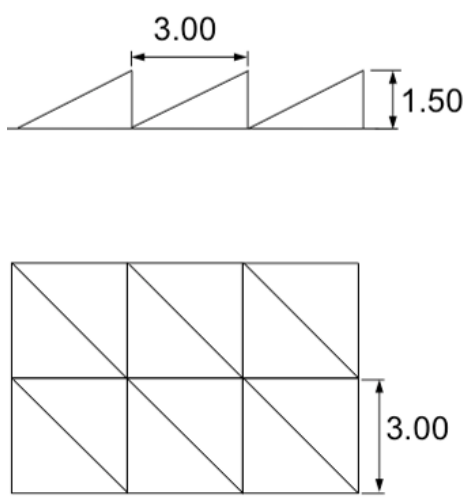

$S / H=2.0 \quad W / H=0$

Figure 2 Friction plates studied: (i) photograph of a quadrant; (ii) schematics with dimensions of the protruberances. (a) plate A, pyramidal; (b) plate B, small studs , (c) plate $\mathrm{C}$, large studs and $(d)$ plate $\mathrm{D}$, saw-toothed. $S$-spacing; $H$-height; $W$-width. All dimensions in $\mathrm{mm}$. 


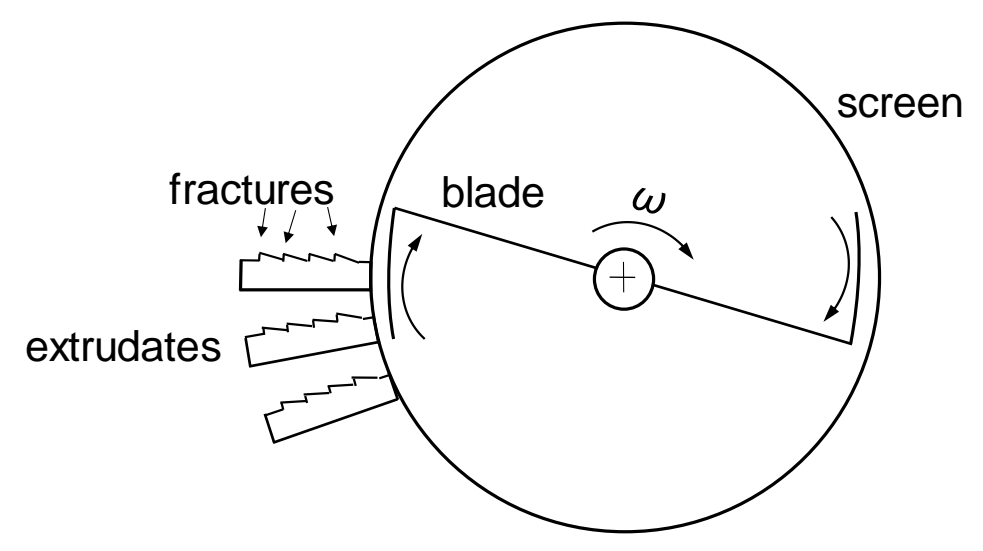

Figure 3 Schematic of basket extruder showing the location of extrudate fractures. 
$D=1 \mathrm{~mm}$

(a)

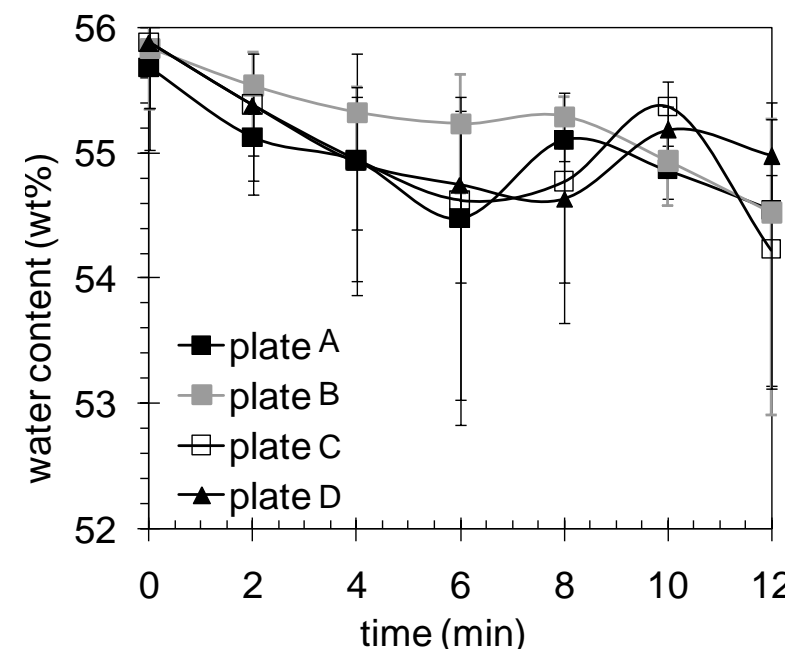

(b)

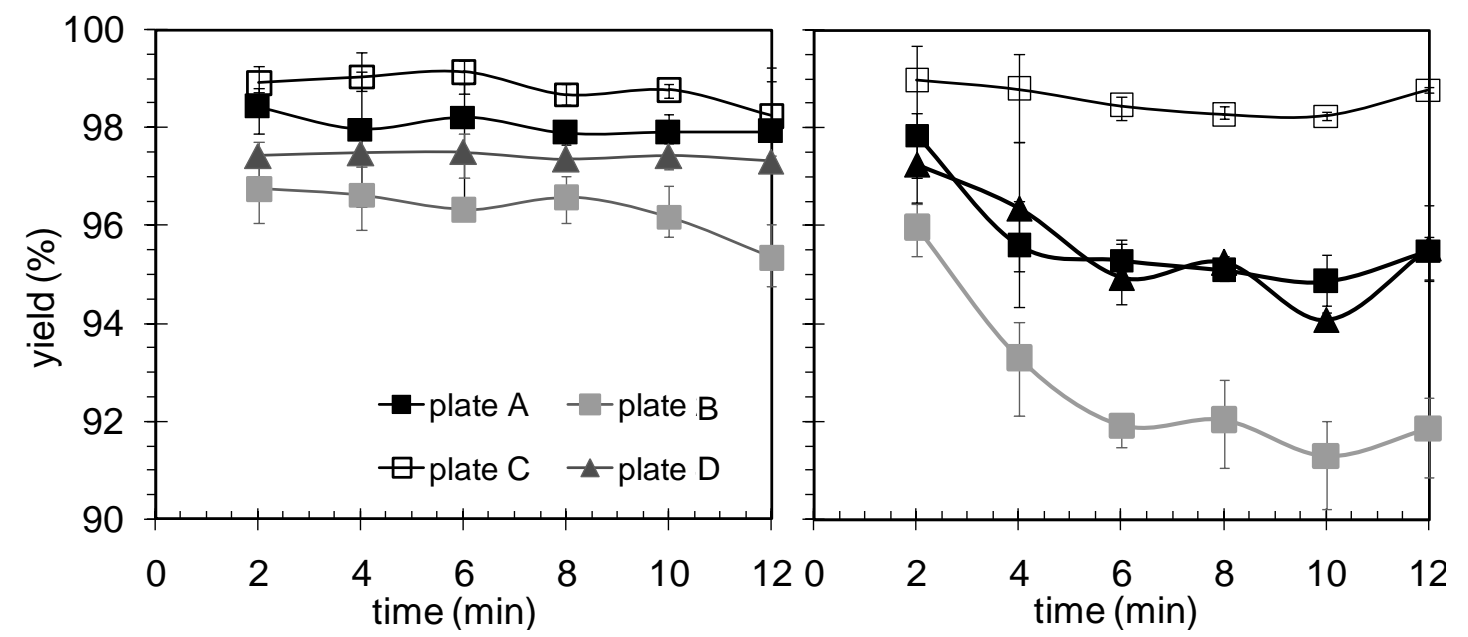

Figure 4 Evolution of $(a)$ spheronisation product water content and $(b)$ pellet yield for different hatching patterns for extrudates of (i) $1 \mathrm{~mm}$ diameter, and (ii) $2 \mathrm{~mm}$ diameter. The data reported are for all material obtained after spheronisation. About $30 \mathrm{~g}$ of extrudates were spheronised at $1600 \mathrm{rpm}$ in each case. Error bars show the range in experimental data sets. 
(i)

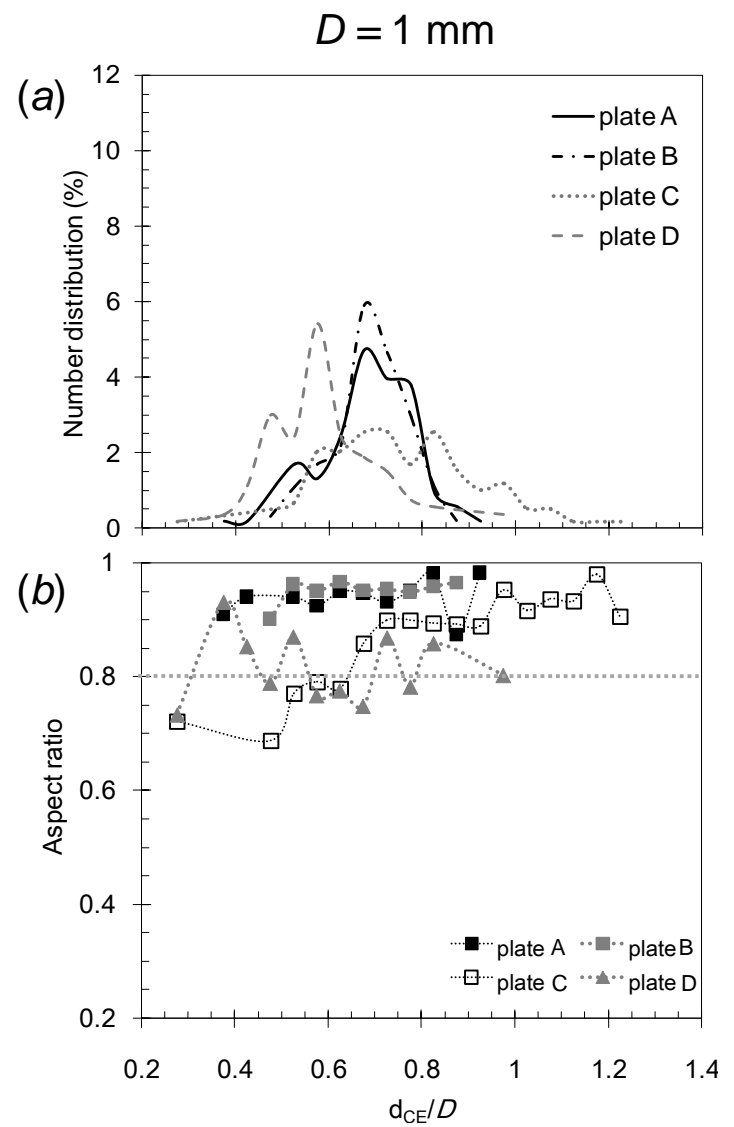

(ii)
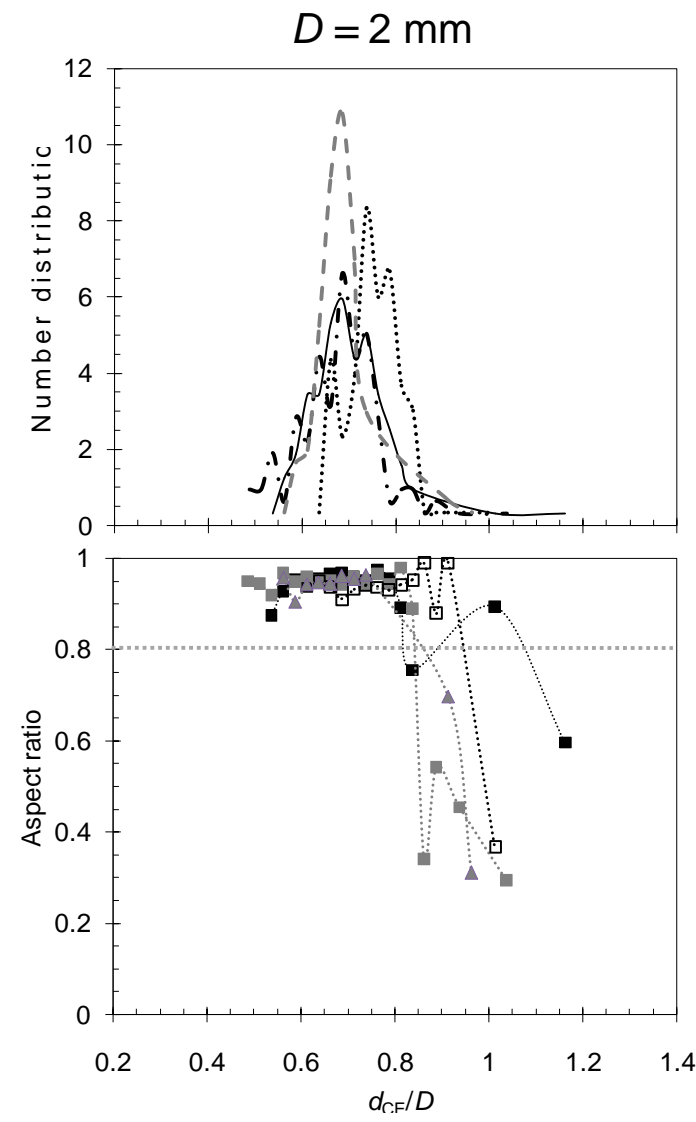

Figure 5 Size and shape distributions of dried pellets obtained after spheronisation at $1600 \mathrm{rpm}$ for $12 \mathrm{~min}$ : (a) number distribution (\%); (b) aspect ratio against $d_{\mathrm{CE}} / D$. Sizes are plotted in dimensionless form, $d_{\mathrm{CE}} / D$. Horizontal dashed line in $(b)$ shows the minimum acceptable aspect ratio of 0.8. The area under each of the number distribution curves is normalised to 1 . 

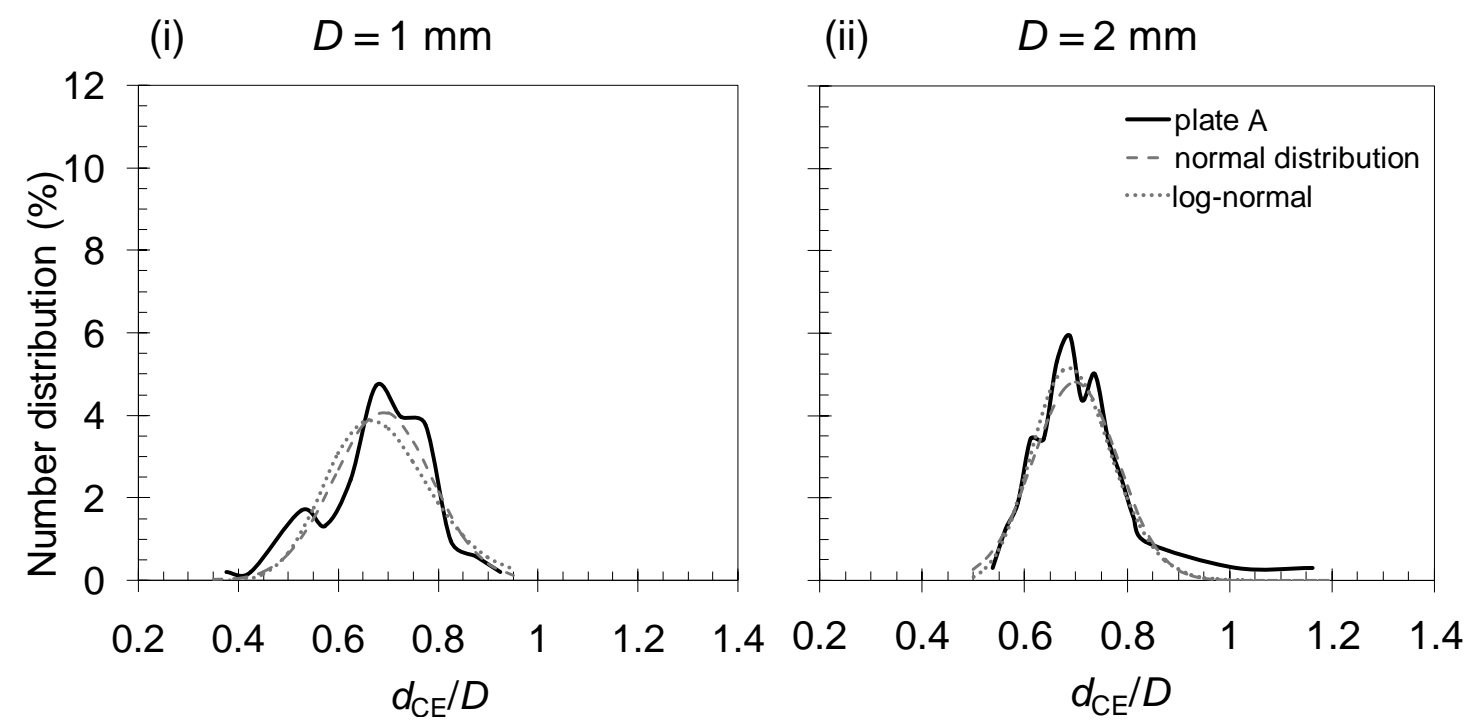

Figure 6 Plate A pellet size distributions (reproduced from Figure 5(a)) alongside fitted normal and log-normal distribution models. Distribution parameters are given in Table 4. The area under each curve is normalised to 1. 
(i)

(a)

(b)
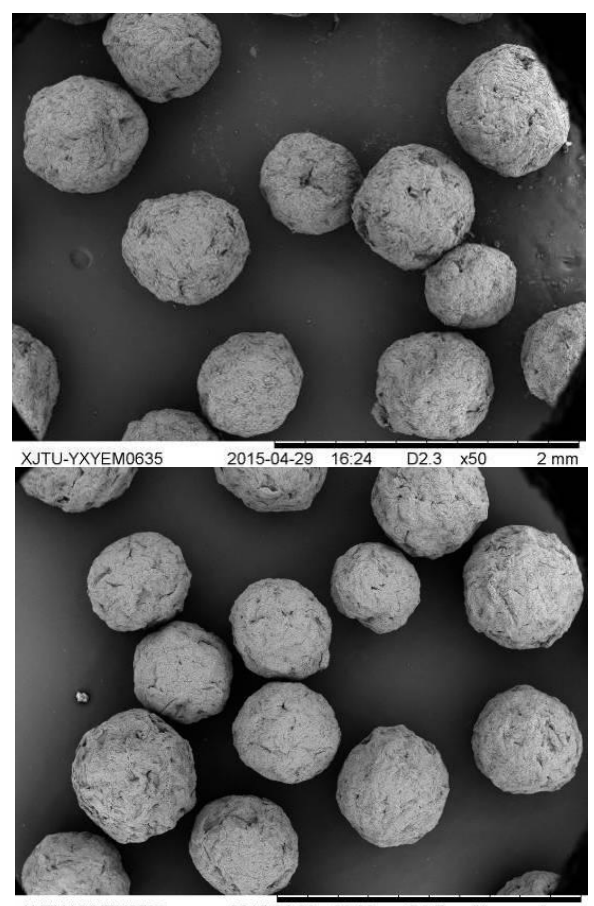

(c)

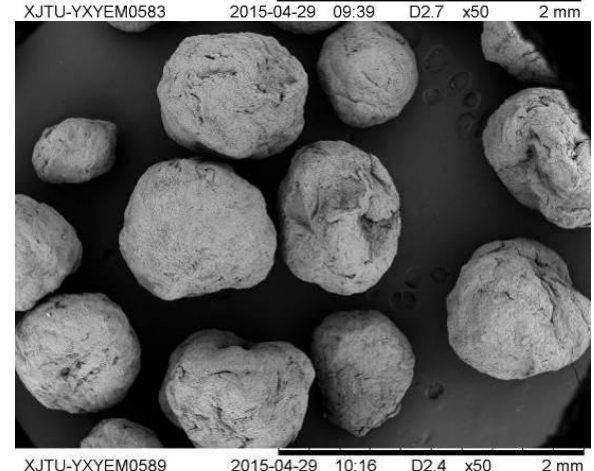

(d)

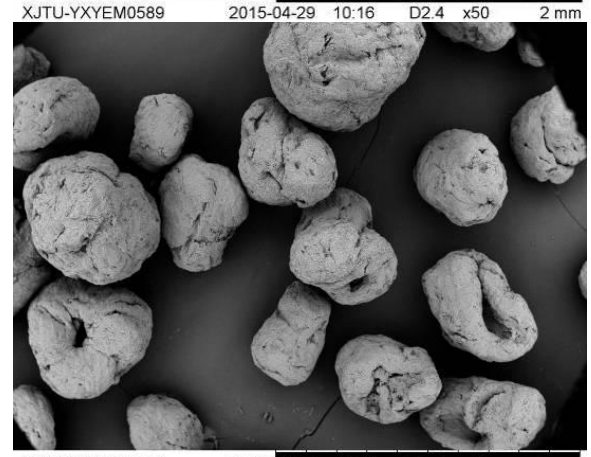

(e)

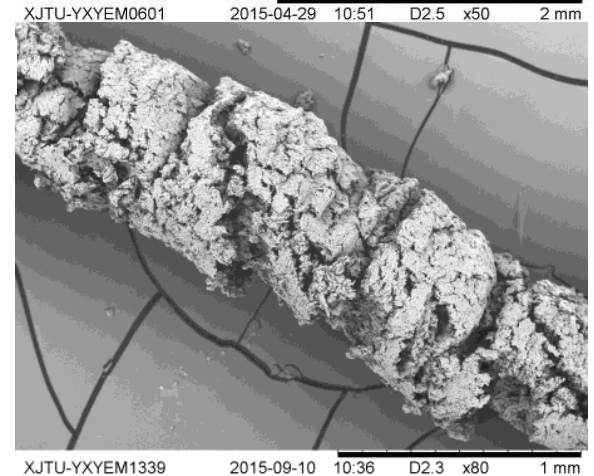

(ii) $\quad D=2 \mathrm{~mm}$
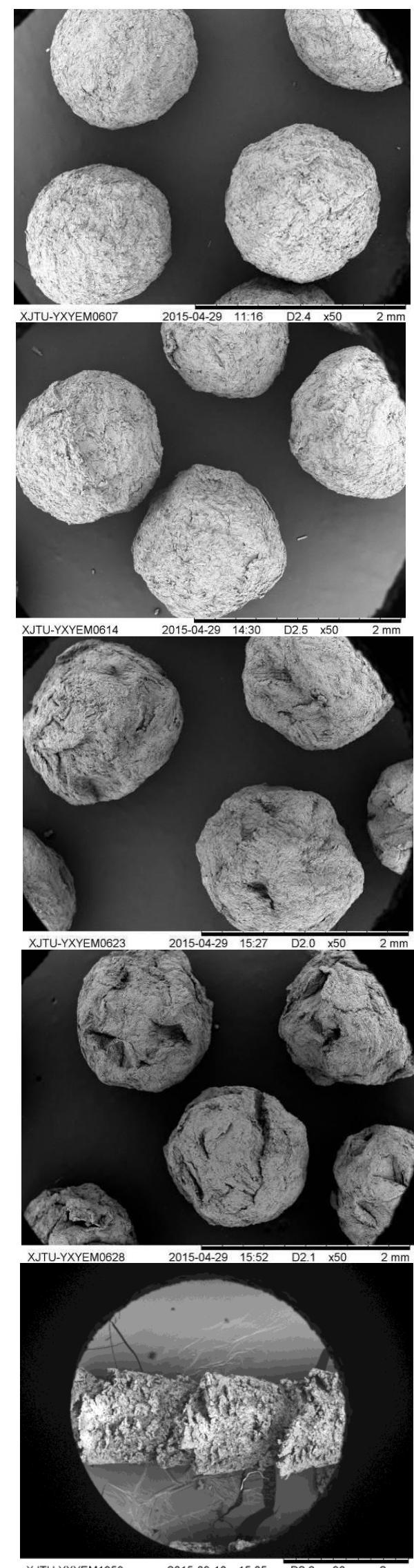

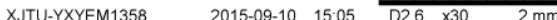

Figure 7 SEM images of pellets produced after spheronisation at $1600 \mathrm{rpm}$ for $12 \mathrm{~min}$ on plate $(a) \mathrm{A},(b) \mathrm{B},(c) \mathrm{C}$ and $(d) \mathrm{D}$ using $(e)$ extrudates from screens with hole size $D=$ (i) $1 \mathrm{~mm}$, (ii) $2 \mathrm{~mm}$. 
Table 1 Dimensions of extruder screen holes and extrudate density (given as average \pm experimental data range) for extrusion of $45 \mathrm{wt} \% \mathrm{MCC} /$ water paste

\begin{tabular}{ccc}
\hline Screen hole diameter $(\mathrm{mm})$ & 1.0 & 2.0 \\
\hline Screen thickness $(\mathrm{mm})$ & 1.0 & 1.0 \\
$\begin{array}{c}\text { Percentage of screen face } \\
\text { occupied by hole area }\end{array}$ & $19.0 \%$ & $24.5 \%$ \\
Extrudate density $\left(\mathrm{kg} \mathrm{m}^{-3}\right)$ & $775 \pm 60$ & $736 \pm 10$ \\
\hline
\end{tabular}


Table 2 Statistical analysis of yield for spheronisation at $1600 \mathrm{rpm}$ using different friction plates

\begin{tabular}{ccc}
\hline \multirow{2}{*}{ plate } & \multicolumn{2}{c}{$\begin{array}{c}\text { Yield } \\
\text { (mean } \pm \text { standard deviation) }\end{array}$} \\
\cline { 2 - 3 } & 1 mm i.d. screen hole & $2 \mathrm{~mm}$ i.d. screen hole \\
\hline A & $98.1 \pm 0.5$ & $95.7 \pm 1.2$ \\
B & $96.3 \pm 0.7$ & $92.7 \pm 1.8$ \\
C & $98.8 \pm 0.5$ & $98.6 \pm 0.5$ \\
D & $97.4 \pm 0.3$ & $95.6 \pm 1.2$ \\
\hline
\end{tabular}


Table 3 Pellet size and shape parameters (mean \pm standard deviation) obtained by image analysis of 120 pellets (see Figure 5).

\begin{tabular}{ccccc}
\hline \multirow{2}{*}{$\begin{array}{c}\text { Screen hole } \\
\text { diameter, } D \\
(\mathrm{~mm})\end{array}$} & plate & $d_{\mathrm{CE}} / D$ & mean aspect ratio & mean circularity \\
\cline { 3 - 5 } & A & $0.69 \pm 0.10$ & $0.94 \pm 0.05$ & $0.88 \pm 0.02$ \\
& B & $0.69 \pm 0.08$ & $0.95 \pm 0.03$ & $0.88 \pm 0.01$ \\
1 & C & $0.76 \pm 0.16$ & $0.86 \pm 0.13$ & $0.84 \pm 0.05$ \\
& D & $0.59 \pm 0.16$ & $0.79 \pm 0.16$ & $0.83 \pm 0.06$ \\
& A & $0.70 \pm 0.08$ & $0.95 \pm 0.08$ & $0.86 \pm 0.07$ \\
& B & $0.68 \pm 0.09$ & $0.93 \pm 0.11$ & $0.86 \pm 0.06$ \\
& C & $0.76 \pm 0.06$ & $0.93 \pm 0.07$ & $0.85 \pm 0.03$ \\
& D & $0.68 \pm 0.05$ & $0.94 \pm 0.07$ & $0.85 \pm 0.05$ \\
\hline
\end{tabular}


Table 4 Results of regression fitting of the pellet $d_{\mathrm{CE}} / D$ data to normal and log-normal distribution models

\begin{tabular}{|c|c|c|c|c|}
\hline Plate & $A$ & B & $\mathrm{C}$ & $\mathrm{D}$ \\
\hline \multicolumn{5}{|l|}{$D=1 \mathrm{~mm}$} \\
\hline $\begin{array}{l}\text { Type of the best fit } \\
\text { model }\end{array}$ & $\mathrm{N}^{(1)}$ & $\mathrm{N}$ & $\mathrm{N}$ & $\mathrm{LN}^{(2)}$ \\
\hline Log likelihood $^{(3)}$ & 96.5 & 147.7 & 45.9 & 82.1 \\
\hline$\mu^{(4)}$ & $0.69 \pm 0.01$ & $0.69 \pm 0.01$ & $0.76 \pm 0.02$ & $-0.55 \pm 0.02$ \\
\hline$\sigma^{(4)}$ & $0.10 \pm 0.01$ & $0.08 \pm 0.01$ & $0.16 \pm 0.01$ & $0.20 \pm 0.01$ \\
\hline \multicolumn{5}{|l|}{$D=2 \mathrm{~mm}$} \\
\hline $\begin{array}{l}\text { Type of the best fit } \\
\text { model }\end{array}$ & LN & LN & LN & LN \\
\hline Log likelihood & 145.6 & 124.2 & 171.1 & 193.0 \\
\hline$\mu$ & $-0.36 \pm 0.01$ & $-0.39 \pm 0.01$ & $-0.28 \pm 0.01$ & $-0.39 \pm 0.01$ \\
\hline$\sigma$ & $0.11 \pm 0.01$ & $0.14 \pm 0.01$ & $0.08 \pm 0.01$ & $0.07 \pm 0.01$ \\
\hline
\end{tabular}

(1) $\mathrm{N}$ - normal distribution

(2) $\mathrm{LN}$ - log-normal distribution

(3) Log likelihood - Natural logarithm of the likelihood. The law of likelihood stated by Edwards (1972): within the framework of a statistical model, a particular set of data supports one statistical hypothesis better than another if the likehood of the first hypothesis, on the data, exceeds the likelihood of the second hypothesis.

(4) $\mu$ and $\sigma$ are the parameters for the best fit model. 
Table 5 Ranking of friction plate geometries in terms of performance factors

\begin{tabular}{lllll}
\hline Plate Geometry $\quad$ Yield & Size $^{(1)} \quad$ Shape $^{(2)}$ & Meso-structure & $\begin{array}{l}\text { Overall } \\
\text { ranking }\end{array}$
\end{tabular}

$\begin{array}{llll}\text { Figure } 4 & \text { Table } 3 & \text { Table } 3 & \text { Figure } 7\end{array}$

$$
D=1 \mathrm{~mm}
$$

$\begin{array}{lllllll}\text { A } & \text { Pyramidal } & 2 & 1= & 2 & 2 & 1= \\ \text { B } & \text { Small stub } & 4 & 1= & 1 & 1 & 1= \\ \text { C } & \text { Large stub } & 1 & 4 & 3 & 3 & 3 \\ \text { D } & \text { Saw-toothed } & 3 & 3 & 4 & 4 & 4\end{array}$

$D=2 \mathrm{~mm}$

\begin{tabular}{lllllll} 
A & Pyramidal & $2=$ & 3 & 1 & 1 & 1 \\
B & Small stub & 4 & 4 & $3=$ & 2 & 4 \\
C & Large stub & 1 & 2 & $3=$ & 3 & $2=$ \\
D & Saw-toothed & $2=$ & 1 & 2 & 4 & $2=$ \\
\hline
\end{tabular}

(1) based on narrowness of distribution.

(2) based on aspect ratio. 